Article

\title{
Scaling up and out as a Pathway for Food System Transitions
}

\author{
Hannah Pitt ${ }^{1, *}$ and Mat Jones ${ }^{2}$ \\ 1 Sustainable Places Research Institute, Cardiff University, CF10 3AT Cardiff, UK \\ 2 Public Health and Wellbeing Research Group, University of the West of England, BS161QY Bristol, UK; \\ matthew.jones@uwe.ac.uk \\ * Correspondence: PittH2@cardiff.ac.uk; Tel.: +442-920-879-632
}

Academic Editors: Moya Kneafsey and Iain Gordon

Received: 2 August 2016; Accepted: 4 October 2016; Published: 13 October 2016

\begin{abstract}
This paper contributes to the understanding of sustainability transitions by analysing processes of scaling up and out as change pathway. It defines scaling up and out as a distinct form of policy transfer focused on programme implementation, with continuity of actors across jurisdictions. We detail how scaling up and out occurs, introducing a new mechanism to policy transfer frameworks. This is explicated through the case study of Food for Life (FFL), a civil society innovation programme promoting sustainable healthy food in public settings. We highlight why FFL was scaled up and out, how this was achieved, by whom, and the results and success factors. The case study demonstrates the importance of interrogating motivations for transferring policies, and how these influence whether successful outcomes are achieved. This requires a revised framework for analysing policy transfer, with greater attention to the links between motives and outcomes, and a less binary understanding of agents' roles. Where scaling is the mode of policy transfer, we suggest that continuous involvement of at least one transfer agent across the process is significant to success. We conclude by highlighting implications for future research into policy transfer and food system transitions.
\end{abstract}

Keywords: transitions; scaling up; scaling out; policy transfer; public food

\section{Introduction}

The need to change an unsustainable food system seems in little doubt; how this might be effected is a fundamental question for agri-food and sustainability scholars [1]. Desire for change has stimulated a proliferation of alternative food initiatives, but innovations remain piecemeal, making limited impact on the dominant system [2-4]. This resultant gap between ambition and achievement presents a challenge for those facilitating or researching sustainability transitions. Bringing transitions under the spotlight, Hinrichs suggests that there are many potential pathways to food system sustainability the "processes, promises and pitfalls" of which need interrogation [1] (p. 144). We interrogate one such pathway.

Commentators suggest niche or alternative food system innovations should scale to become more widespread making the challenge of enabling alternatives to 'scale up and out' as pressing $[3,5,6]$. Mount identifies this as the next hurdle facing local food systems: "in order to capitalize on the momentum of this movement and to broaden accessibility, local food entities will have to scale-up, engaging either more or larger consumers and producers" [7] (p. 108). Friedman notes the effort to scale up local food supply chains as a long-standing focus of Toronto's community food sector [8]. Those participating in UK food policy networks will have encountered frequent discussion of how to scale. But commentators do not explain why this is a suitable strategy for driving change. Following Hinrichs, it is important to consider the promise and problems of scaling as potential pathway for food systems change. But there is little clarity on what scaling up and out is, hence a key task is 
to define this distinct pathway. Policy is one component of regimes perpetuating unsustainable systems, with transition dependent on policy makers choosing to enact alternative regulation $[9,10]$. Applying the logic of policy transfer to transition therefore contributes understanding of how innovations drive change. Policy transfer analysis complements transition theory as the former attends to actors and agency [11] whilst the latter tends not to [12].

A second challenge is knowing whether scaling up and out is a desirable transition pathway, and why. Proponents assume innovations delivering at a small scale will achieve more if scaled beyond the local. This logic is apparent in transition theories, with scaling up identified as one mechanism for niche innovations to become mainstream $[13,14]$. Although this logic is intuitively appealing, Born and Purcell [15] alert us to the danger of assuming any association between scale and sustainability. A second task for this paper is therefore to identify what makes scaling a desirable transition pathway, and whether it is more so than other modes of policy transfer. This requires better understanding of how it happens, how successful outcomes are promoted and negative ones avoided [16]. The case study demonstrates that transfer agents' motivations are a crucial success factor. We argue that this requires analysts to revisit the question 'why transfer policy?' because placing policy transfers on a continuum between voluntary and coercive over-simplifies drivers, neglecting motivating factors and how transfer agents interact. Closer attention to these is important to understanding the likelihood of successful transfer, and to correctly characterise roles involved. We therefore revise Dolowitz and Marsh's [17] influential framework for policy transfer to support assessment of whether transfer is likely to achieve success.

The paper aims to address two linked questions. Firstly, how can scaling be defined and developed as a framework for conceptualising transitions to food sustainability? Secondly, how can this conceptualisation be used to inform our understanding of the development of food sustainability initiatives? The initial question is addressed through a review of literature, with a focus on the contribution of scholars working in the fields of policy and programme analysis. We then draw upon this material in an organisational case study of Food for Life (FFL), a leading a non-governmental initiative in England aimed at promoting sustainable food in public settings such as schools. The paper concludes with broader reflections and questions for future research.

\section{Literature Review and Conceptual Development}

\subsection{Transitions to Food Sustainability}

Like many seeking to understand sustainability, scholars of food systems have taken interest in transition. This "gradual, pervasive shift from one state or condition to something different" is pertinent to sustainability as actors work to drive change, in this case towards a more sustainable food system [1]. Food systems encompass activities to produce, process, distribute, sell and consume food, which are linked in complex relationships and feedback loops [18]. Today's dominant food system is characterised by highly industrialised production feeding global supply chains where power concentrates with multi-national businesses $[9,19,20]$. Transitions from this towards sustainability are driven by the goal of increasing social justice and reducing environmental damage [19], and increasing resilience to climate change [20]. The many strategies for this include those targeting public procurement and mass institutional catering. Public institutions' purchasing effects significant change because its scale and stability is sufficient to motivate large suppliers and producers to work differently $[18,21]$. Food for Life, a case study focus in this paper, is part of a global movement working to lever change through school food, in response to concerns regarding health and environmental impacts $[5,22]$. Food policy decisions arguably have more traction when targeting public actors than individual consumers or businesses, hence interest in potential to transfer successful policies for sustainable public food.

There is a large and growing literature on sustainability transitions, which we define as "fundamental transformation(s) towards more sustainable modes of production and consumption" [23] 
(p. 955). A number of frameworks, or pathways, have achieved prominence including those concerned with organizational management, social movements and technological innovations [23]. Such ideas have been applied to food system innovations, with Geels' [24] multilevel perspective model particularly popular, e.g., $[2,9,10,25]$. This regards transitions as a result of interaction between regime, landscape and niche. Regime level is the over-arching socio-technical system of rules, structures and organisations which stabilise practice and drive continuity. Landscape level marks deep structural trends which shape the context for actors, only changing slowly. Niches are often the product of community or civil society actors tackling local problems in a zone of experimentation which pulls against forces perpetuating regimes [20]. Innovation occurs at niche level where they find incubation from the regime so can operate under different rules, free from path dependencies. Transition occurs when innovations break out of niches to influence landscape or regime. This might happen through accumulation if an innovation builds momentum within a niche, through change at landscape level creating pressure for change, or when destabilization of the regime opens an opportunity [24].

Applied to food systems, regime represents mainstream approaches dominated by large-scale industrial farming, and lengthy supply chains controlled by powerful agri-businesses [9]. Niche innovations include alternative food networks which bring producers and consumers closer together [2], organic food production [10], and civil society programmes supporting local food activity to shorten supply chains [26]. Strategic niche management can prompt policy change supportive of niche innovations as happened with the expansion of organic food production [10]. The mainstream may react by marginalising niches; particularly strong state control of agri-food systems can limit the potential for transition [20]. A further scenario is one in which alternative food production becomes 'conventionalised', that is a process of transforming an oppositional movement into a highly regulated and capitalised sector that differs little from its conventional counterparts [27,28].

Scaling up is cited as one mechanism spreading niche innovations to prompt transition $[13,14]$. But literatures on transitions theory and food systems lack critical reflection on how scaling functions, its outcomes and desirability. Given the prominence of governance within the food sector [20], policy makers are key transition agents in this context. Yet food system transition through policy and civil society programmes have not been explored as fully as those driven by individual practices. This leads us to regard scaling as a form of policy transfer in which state and non-state actors move and develop a solution. A focus on scaling up and out applies a policy transfer perspective to enhance understanding of transition mechanisms, in turn challenging how policy transfer is analysed.

\subsection{Conceptualising Scaling up and Scaling out}

In this section we review definitions of scaling, before locating it within policy transfer analysis. Definitions of scaling up and out share the notion of seeking to achieve more, reaching more beneficiaries, having greater impact ([29] (p. 733), [30] (p. 15) and [31] (p. 213)). Scaling implies an innovation moved across boundaries to reach more people [32], in the context of food systems meaning more or larger consumers and producers. This might be achieved by transferring alternative production and supply modes to larger businesses, as when practices developed by family farms are adopted by medium scale enterprises [7]. Scaling has also been associated with the process of civil society actors encouraging mainstream institutions to alter practices [18]. In transition terms scaling equates growing a niche, moving into landscape and regime. It occurs through replication [33], a quantitative increase in activity and coverage $[3,29,30]$, or expansion through growth in institutional capacity $[30,34]$. Expansion and replication lead to innovations occupying more or enlarged niches. Alongside this the innovation may evolve to meet new needs [33], moving between niches or 'scaling out' [34-36].

Not all authors distinguish scaling up from out, and distinctions are inconsistent. A definition used by UN agencies [37] and others [29] describes scaling up as: "expanding, adapting and sustaining successful policies, programmes or projects in different places and over time to reach a greater number of people" [34] (p. 1). This implies spatial expansion from local micro action to meso or macro 
level [30,33,38]. Others see scaling up as expansion of institutional capacity [31]. Alternatively, the extension of geographic reach is regarded as horizontal scaling, with vertical scaling representing institutional expansion [35]. A tendency to conflate scaling up and scaling out might be due to the reality that geographical expansion requires organizational growth [35] Common to these definitions is actors' intent for greater impact by crossing jurisdictions [39].

Scaling up and out can occur through policy innovations being shared and mimicked [26] as policy makers consider whether an innovation suits their needs, and whether to adopt it. Policy decisions are significant to transition because policy convergence might create pressure for regime change or facilitate strategic niche management. For example, actors focused on changing food in public institutions seek to influence state investment to lever food system transition $[18,21]$. These processes require greater recognition within transition theory, as pathways by which innovations influence beyond their niche are under-explored [14]. Applying a policy transfer lens highlights the role of decision makers, addressing transition theory's neglect of actors and agency, and agents acting across scales [32]. We consider policy transfer a potential driver of transitions, emphasising scaling as a distinct mechanism.

\subsection{Scaling as Policy Transfer}

Scaling as "the practice of introducing proven interventions into new settings with the goal of producing similarly positive effects in larger, more diverse populations" [30] (p. 15) clearly overlaps with policy transfer. Policy transfer centres on intentional knowledge exchange between decision makers $[11,17,40,41]$. It is misleading to see these processes happening spontaneously as they are driven by agents, and require careful planning and facilitation [31,39]. This is made easier by the support of political leaders [35] and thus mediated by power relations. Scaling up and out happens through innovations being shared and mimicked either through loose inspiration or direct implementation [29]. Central to this is learning between policy makers as they consider whether an innovation is suited to their needs. Should policy makers choose to transfer an innovation the result would be its replication in a new space, hence it scales up or out. This can be interpreted as a form lesson drawing as decision makers work to understand what has worked elsewhere and use this knowledge to influence their own programmes [42].

We identify scaling up and out as a form of policy transfer focused on movement of programmes-delivery of specific means of action on a problem [17]. This gives it a distinct position on Dolowitz and Marsh's framework for analysing policy transfer. Firstly, 'what is transferred' concerns implementation through practical action and supporting infrastructure. The degree of transfer is towards the copying end of the spectrum, although a programme reproduced in new contexts adapts to new conditions $[29,30,43-45]$, so is an imprecise copy. Scaling includes transfers not just across spatial jurisdictions-regions or countries-but between policy jurisdictions, hence our definition:

Scaling is the deliberate effort to transfer a policy programme over space, time or function through spread, renewal, and diversification. The original programme is imitated in new contexts, by actors who retain a role in delivery. Expansion across space and time represents scaling up; diversification into new functions is scaling out.

One defining feature is outside Dolowitz and Marsh's framework: at least one actor remains involved in delivery as the programme transfers across jurisdictions. The case study illustrates this as success factor and significant influence on policy makers' involvement in the transfer. Scaling therefore suggests a need to reconsider why policy transfers happen, and how to interpret their success, with the analytical framework amended accordingly.

Introducing scaling as a mode of policy transfer addresses limitations in existing analysis of solutions moving between policy makers. Firstly, studies tend to be descriptive cases [41] lacking comparative analysis, so the relative merits of different approaches are unknown. Analysis often stops at point of transfer so outcomes are neglected; there is a need for greater attention to whether transfers succeed and why $[17,44-46]$. A related gap concerns lack of insight into why decision 
makers transfer policy. The question 'why transfer?' has been mooted since Dolowitz and Marsh's framework, but answers focus on whether transfers are coerced or voluntary [47]. This offers limited parameters for understanding what motivates transfers, and over-simplifies factors driving policy making [48,49]. Considering the appeal of scaling reveals a complexity of reasons for transfers, suggesting a need to consider different actors' motivations and how these influence outcomes. This advances understanding of why policy transfer is attractive to decision makers, answering criticism that it is not distinct from general policy making $[11,50]$ and begins to identify modes of transfer conducive to successful outcomes.

Some policy transfer analysis explores the movement of ideas or information [41], but programmes also move [17]. Our analysis demonstrates that policy and programme are not discrete entities as delivery influences policy, whilst policy decisions aid programme growth and transfer. Scaling reveals complex interactions as solutions evolve, challenging how policy analysts regard transfer agents. Dolowitz and Marsh ask 'who is involved in transfer?', and categorise state and non-state actor [17]. Through its evolution policy transfer research has broadened this typology to include more non-governmental actors [47], which reflects the influence a more dispersed and governance-informed analysis of policy processes. How this diversity affects motivations for policy transfer requires attention, as distinct actors are likely to have specific goals. Such multiplicity is acknowledged in more recent work influenced by social constructivism [47]. From this perspective a longer list of potential transfer agents still will not capture the process's complexity if it assumes a linear process passing knowledge from sender to recipient [48-50]. This is challenged by mobility perspectives which recognize a fluid process with agents' roles interacting and morphing [48-50]. Scaling up and out as transfer mode supports a less linear interpretation not founded on a bilateral sender-recipient relationship $[49,51]$ as the case study demonstrates blurred divisions between state and non-state actors. Non-governmental organisations deliver for government, programmes and policies are shaped collaboratively. This suggests a need to reframe analysis of transfer agents around the question 'what are the roles of those involved?', shifting focus from who to what they do. Attention to roles corrects a tendency to emphasise what is transferred to the neglect of how it happens [49], and why [50].

In summary, adding scaling up and out to policy transfer frameworks sheds light on a previously neglected mode, adding detail on transfer mechanisms. It confirms the need to consider relationships between actors as complex and iterative rather than bilateral, and the transfer process as non-linear. Scaling challenges the view that ideas exchanged between policy makers are rarely implemented $[42,43,52]$ by focusing on programme delivery. However, that programmes evolve as they scale supports the suggestion that solutions mutate [50]. The case study demonstrates the significance of motivations, and how they alter the likelihood of success. On this basis we amend Dolowitz and Marsh's framework for policy transfer [17] prioritising questions which better interrogate the likelihood of successful outcomes.

Table 1 presents the amended framework. A key amendment is re-framing the question 'why transfer?' away from answers on a continuum between 'want to' and 'have to'. Scaling is a process driven partly by non-government bodies working to grow their programme, partly by policy makers seeking proven solutions. Where these motivations align transfer occurs; there must be a coincidence of those driving an innovation with those shaping opportunities for scaling [32]. Reframing responses to 'why transfer?' as motivations better accounts for actors' diverse motives, and uncovers their goals for policy transfer. Focusing on goals provides parameters for judging policy transfer success: if goals are achieved the transfer was successful. We now elaborate an example of scaling up and out, applying questions from the amended framework. 
Table 1. A revised policy transfer framework.

\begin{tabular}{|c|c|c|c|c|c|c|c|c|}
\hline $\begin{array}{l}\text { Dolowitz and } \\
\text { Marsh's } \\
\text { Questions } \\
\end{array}$ & Why Transfer? & Who Is Involved? & $\begin{array}{l}\text { What Is } \\
\text { Transferred? }\end{array}$ & From Where? & $\begin{array}{l}\text { Degree of } \\
\text { Transfer? }\end{array}$ & $\begin{array}{l}\text { Constraints on } \\
\text { Transfer? }\end{array}$ & $\begin{array}{l}\text { How to Demonstrate } \\
\text { Policy Transfer? }\end{array}$ & $\begin{array}{l}\text { How Transfer } \\
\text { Leads to Policy } \\
\text { Failure? }\end{array}$ \\
\hline How they answer & $\begin{array}{l}\text { Voluntary-coercive } \\
\text { continuum, i.e., 'want } \\
\text { to' or 'have to' }\end{array}$ & $\begin{array}{l}\text { List of state and } \\
\text { non-state agents, } \\
\text { e.g., civil servants, } \\
\text { NGOs }\end{array}$ & $\begin{array}{l}\text { Policies, programs } \\
\text { or negative lessons }\end{array}$ & $\begin{array}{l}\text { Past to present, } \\
\text { within country, } \\
\text { e.g., city to city, or } \\
\text { cross national }\end{array}$ & $\begin{array}{l}\text { Copying, emulation, } \\
\text { inspiration or } \\
\text { a mixture }\end{array}$ & $\begin{array}{l}\text { Policy complexity, } \\
\text { feasibility, } \\
\text { past policies }\end{array}$ & $\begin{array}{l}\text { Reports, } \\
\text { media }\end{array}$ & $\begin{array}{l}\text { Uninformed } \\
\text { transfer, incomplete } \\
\text { or inappropriate } \\
\text { transfer }\end{array}$ \\
\hline $\begin{array}{c}\text { Revised } \\
\text { Questions }\end{array}$ & $\begin{array}{l}\text { What Motivates } \\
\text { Transfer? }\end{array}$ & $\begin{array}{l}\text { What Roles and Who } \\
\text { Fulfils Them? }\end{array}$ & & & $\begin{array}{c}\text { How Does Transfer } \\
\text { Proceed? }\end{array}$ & & What Is the Outcome? & $\begin{array}{c}\text { What Contributes } \\
\text { to Success? }\end{array}$ \\
\hline $\begin{array}{l}\text { Answers from } \\
\text { scaling Food } \\
\text { For Life }\end{array}$ & $\begin{array}{l}\text { NGO: seeking to } \\
\text { expand program } \\
\text { achievements, good } \\
\text { food for all, } \\
\text { commissioner } \\
\text { encouragement. } \\
\text { Local government } \\
\text { officials: seeking } \\
\text { effective, low risk } \\
\text { policy solutions. } \\
\text { Public institutions: } \\
\text { seeking proven } \\
\text { solutions, encouraged } \\
\text { by national policy. }\end{array}$ & $\begin{array}{l}\text { NGO: raise problem, } \\
\text { promote programme, } \\
\text { develop evidence base, } \\
\text { design \& deliver } \\
\text { programme. } \\
\text { Local govt: fund } \\
\text { programme delivery, } \\
\text { shape program design. } \\
\text { Policy network: } \\
\text { encourage peers to } \\
\text { implement } \\
\text { programme. }\end{array}$ & $\begin{array}{l}\text { Programme } \\
\text { delivery model: } \\
\text { FFL local } \\
\text { commission. } \\
\text { Program design: } \\
\text { FFL framework for } \\
\text { whole settings } \\
\text { approach. }\end{array}$ & $\begin{array}{l}\text { Between local } \\
\text { government areas. } \\
\text { Between policy } \\
\text { jurisdictions: from } \\
\text { one public food } \\
\text { setting to others. } \\
\text { Between local and } \\
\text { national policy for } \\
\text { public food. }\end{array}$ & $\begin{array}{l}\text { Scaling up through } \\
\text { programme } \\
\text { expansion into } \\
\text { multiple local } \\
\text { commissions. } \\
\text { Scaling out through } \\
\text { programme } \\
\text { diversification into } \\
\text { new settings. } \\
\text { Supported by } \\
\text { national policy } \\
\text { influenced by FFL. }\end{array}$ & $\begin{array}{l}\text { Competition from } \\
\text { other programs. } \\
\text { Limited local } \\
\text { government } \\
\text { funding for } \\
\text { program delivery. } \\
\text { Limited reach of } \\
\text { policy networks. }\end{array}$ & $\begin{array}{l}\text { Goals for more } \\
\text { sustainable food met in } \\
\text { many schools. } \\
\text { Goals for more } \\
\text { sustainable food partially } \\
\text { met in other } \\
\text { public institutions. } \\
\text { National food policy } \\
\text { changed to encourage } \\
\text { sustainable food in } \\
\text { some settings. }\end{array}$ & $\begin{array}{l}\text { FFL expertise and } \\
\text { experience applied } \\
\text { across jurisdictions. } \\
\text { Work to distinguish } \\
\text { variable and } \\
\text { invariable aspects } \\
\text { to evolve } \\
\text { program design. } \\
\text { Investment in } \\
\text { scaling strategy } \\
\text { and capacity. }\end{array}$ \\
\hline
\end{tabular}




\section{Programme and Case Study Methodology}

\subsection{Food for Life Programme}

Food for Life was established by the Soil Association, an NGO campaigning for "healthy, humane and sustainable food, farming and land use" [53]. From 2007 the FFL partnership operated as a coalition of five charities working to change food cultures by "reach(ing) out through schools to give communities access to seasonal, local and organic food, and to the skills they need to cook and grow fresh food" [54]. FFL takes a whole setting or organisation approach to food, integrating action on health and sustainability.

Schools enrol with FFL then gain awards recognising progress in food leadership and food culture, food quality, food education, community and partnerships. Schools teach practical food skills and integrate them into the curriculum; they are encouraged to involve parents, staff and pupils in changing mealtimes and through extra-curricular activities. FFL encourages school caterers to use more seasonal, local, organic and ethically sourced produce, with a Catering Mark accrediting good practice. The partnership supports through training, advice, resources and by sharing information about schools' progress. Charitable grants to FFL and investment by local commissioners allows support to schools without charge.

By the end of 2015, 5500 schools in England had registered online with the FFL scheme and 21 local authorities had commissioned FFL as an area-based schools programme with supplementary training and support for educational and catering staff. FFL is closely linked to the Food for Life Catering Mark (FFLCM) also led by the Soil Association. The mark involves an independent audit of caterers, offering accreditation for raising food standards. This accreditation demonstrates that an organisation meets the food quality requirements of FFL's framework. Organisations in varied sectors have gained FFLCM accreditation (e.g., defence and hospitals), including large catering contractors working across settings. By 2015, FFL Catering Mark meals were being served in over 25\% schools in England, 20\% universities, over 300 nurseries and over 100 care homes and hospitals [55].

FFL seeks to influence food systems in two ways. The programme encourages public institutions to use more local and organic produce, and menus less reliant on meat, supporting food production with reduced environmental impacts [56]. Secondly, FFL develops knowledge and skills for buying, cooking and growing food to enable enduring lifestyle changes favouring sustainable food choices. Institutions can only obtain an FFL award by providing documentary evidence that they have met a set of criteria concerned with menu changes, ingredient spend, educational reform, leadership and consultation. Awards are categorised at bronze, silver and gold levels to reflect the scope and scale of reforms implemented. Previous research has found that the award levels serve as an indicator of the scale of impact on sustainable food systems [57], for example with respect to greater procurement from local or organic food producers and suppliers [56]. Impacts on the wider consumption behaviours of service users, for example the household food purchases of school parents, is less clearly evidenced although self-report surveys suggest a positive influence [58] FFL presents a valuable case of niche influencing agri-food systems because it is regarded as the "the gold standard" in sustainable school food but had been confined to "islands of good practice" [21], within a public food regime centred on low-cost mass-catering [5]. FFL has sought to scale up and out, with the ambition to bring 'good food to all', presenting an opportunity to analyse scaling processes.

\subsection{Case Study Methodology}

A case study approach was used to examine processes of scaling as a pathway for food transitions. The study was informed by realist evaluation principles which seek to understand the context, mechanisms and outcomes of the programme through interrogating programme delivery processes [59]. These data were based in the interpretations, or 'theories of change', held by lead informants involved in the implementation or receipt of the programme [60]. This research formed part of a wider 
project examining FFL between 2014 and 2015, which involved understanding the evolution of FFL's commissioned programme and its spread from schools to other settings such as hospitals.

\subsection{Methods}

The study adopted qualitative methods in the collection and analysis of programme documentation, observation of partnership meetings and semi-structured interviews. Researchers sought to interview lead representatives from all 11 local authorities that had been operating an FFL commission for at least 12 months; 10 accepted. Interviews were held with 13 FFL staff (two managers developing commissioning nationally, two regional commissioning managers, nine local programme managers). Discussion with FFL staff identified supplementary research participants offering insight into strategic work to expand the programme, and experience of scaling activity. Other aspects of the research project focused on delivery in schools and other settings, allowing researchers to draw on wider knowledge of FFL. Documents and transcribed interviews were analysed thematically with findings cross-checked between researchers. The research received ethical approval by the University Research Ethics Committee.

\section{Case Study Results and Discussion}

Table 1 summarises the overall results of applying policy transfer framework in the context of this case study research. The following sections expand upon and discuss each area.

\subsection{What Is Transferred and How Does Transfer Proceed?}

The FFL partnership was the innovating organisation, involved in delivery across the programme's transfer. FFL's first target group for policy transfer were public health officials responsible for commissioning school food programmes. As FFL expanded its focus to other public institutions, decision makers in other jurisdictions became targets. From its inception in 2007 until 2012 FFL centred on individual schools choosing to engage, whilst the partnership promoted participation. Geographic 'hotspots' emerged where a significant number of schools were FFL-active; shared catering contracts and pre-existing educational collaborations lent impetus to these clusters. At this stage the innovation grew by replicating within schools; its niche enlarged. This created pressure for wider change by increasing demand for sustainable produce, pushing suppliers to re-consider their sourcing. Path dependencies within the mass-catering sector were broken as companies established new supply contracts with alternative and local producers. These supply routes were opened to the wider market, affecting actors outside the niche, influencing the wider school food system.

Niche expansion accelerated when local government public health officers in one hotspot identified an opportunity to support FFL as a commissionable programme delivering public health outcomes. With FFL they devised a package which local policy makers could commission the partnership to deliver:

- a local programme manager providing coordination and support,

- a training programme,

- $\quad$ support for school caterers to achieve the FFL Catering Mark, and

- support for schools to achieve FFL Awards.

The commission was designed for local authorities to 'buy' through commissioning processes. At this point scaling up as policy transfer truly began as successive local government public health departments adopted the commissioned programme and FFL promoted it to potential commissioners. New commissions meant more schools engaged, the innovation grew. It spread between neighbouring local authorities, resulting in 10 commissions by 2014. Transfer initially concentrated in regions where food or obesity policy networks disseminated knowledge between neighbouring commissioners. Wider geographic spread was promoted by a later strategy targeting local authorities in regions with lower engagement. 
This replication over space represents scaling up, supported by concurrent growth in FFL as an organisation. It was an iterative learning process during which stakeholders identified hard, invariable dimensions core to successful delivery, and soft elements adaptable to local context [28]. Invariable elements included the award framework, whilst the mode of support to schools was variable: some commissions targeted certain schools whilst others took a universal approach.

FFL scaled over space by working in more schools, then more commissioned areas, and over time through renewed involvement. Growth accelerated when commissioning introduced a strategic system for engaging schools across an area, and a programme transferable between local governments. Fundamental to these processes were the partnership's will to work with as many schools as possible, and their ability to gain support from local decision makers who could facilitate this.

Next FFL sought funding to diversify beyond schools through scaling out into other institutions that might adopt a similar whole setting approach to food. The partnership drew on expertise in school food to transfer the programme to care homes, universities and hospitals. Core aspects of the school programme were adapted to create parallel frameworks suiting other organisations' priorities. The partnership's links to local governments who commissioned the programme for schools connected them to providers of early years education, helping FFL scale into these. Similar connections encouraged health care trusts to implement FFL; here scaling was facilitated by the partnership's campaigning for better hospital food. FFL was working to influence national policy for hospital food, urging government to introduce incentives for better catering. One local commissioner noted that the introduction of a financial incentive to improve patient food was instrumental in encouraging his health trust to engage FFL.

To scale out into new settings FFL had to identify invariable aspects which made the programme work in schools and translate them:

The Food For Life USP [Unique Selling Proposition] coming out of the schools was the whole setting approach encapsulated in the award framework [... ] we have learned how valued it is to have a series of stepping stones and a journey that schools and other institutions can take where they can benchmark. (FFL manager)

This whole setting approach was revised for each setting, with some elements remaining consistent. Establishing a cross-school group focused on food was identified as essential to delivery; this was adapted to other settings as a cross-departmental group. A focus on learning to grow food in schools evolved into patient involvement in therapeutic horticulture. Adapting the whole setting framework was done collaboratively between FFL staff, and pilot institutions in each new setting. This brought together FFL's expertise in sustainable catering and changing food cultures, and institutions' knowledge of their contexts. Continued involvement of the FFL partnership across the transfer process ensured their understanding of a successful programme for sustainable public food was applied throughout.

This section has described how FFL scaled up and out in multiple stages and through multiple influential actors exchanging knowledge in several directions. We now elaborate on the nature of scaling by addressing other new questions in our policy transfer framework.

\subsection{Why Transfer: Motives for Scaling FFL}

Typically, the answer to 'why transfer policy?' has focused on whether this was coerced or voluntary. FFL's scaling does not fit this continuum because actors had different drivers. National policies requiring action on public health compelled transfer between local governments but they could implement alternative programmes. No actor was coerced, rather they encouraged each other to implement and evolve FFL. This suggests other factors more significant than the degree of coercion. For the FFL partnership the potential to scale was ever present:

We are always thinking from the outset where is this work going and how might it be supported in taking it forward (FFL manager). The will for expansion is in their nature: I suppose the other 
drivers were about the way in which we operate, the Soil Association operates as an agent for change I suppose, looking to shine a spotlight on where there are problems and innovate solutions and then go onto deliver them. (FFL manager)

FFL want to maximise numbers of people eating 'good food': the rationale is about changing social norms, a big part of which is around changing the availability [of unhealthy food] in all these keys settings where people live out of their daily lives. (FFL manager)

Achieving this requires change at regime and landscape level so attention had to move beyond schools. Diversification into new niches was also driven by demand as FFL developed a reputation for good work with schools which led other institutions to approach them. This coincided with interest from local government public health commissioners in a life course approach to good food meaning: looking at which of the institutions that are responsible for feeding sections of the population at different stages (FFL manager).

FFL in schools met commissioners' need for action to encourage healthy childhood weight, a national public health priority [61]. Addressing a national concern provided a good basis for scaling up. These commissioners work on health needs across demographics, taking a systems approach to tackling health inequalities and issues such as obesity; transferring FFL out offered synergy across this activity. One described how prior to FFL's activity to scale out her team was considering moving it from schools; they already worked with hospitals so bringing FFL in "felt like a natural extension". This transfer "built momentum", driving moves into other jurisdictions including social care, and linked activities into "a more integrated approach". Local governments which saw themselves as food sustainability leaders wanted to build on FFL's work with schools to advance progress.

Commissioners described advantages of working with an NGO partner like the FFL partnership which encouraged them to support scaling: they bring good practice from elsewhere, offer an alternative perspective and encourage a holistic outlook on food. Rather than looking to alternative programmes and NGOs they preferred to scale work with FFL. Commissioners said that they knew and trusted the partnership and appreciated their staff's approach. Policy makers follow lines of least resistance by looking for short cuts and solutions close by [53]. Programme transfer was a lower risk option for local government actors motivated by the need for proven, successful solutions and trusted partners.

FFL staff and commissioners suggested independent evaluation of the programme was crucial in convincing others to invest in the programme. This is consistent with a political culture favouring evidence based policy [11,51]. Interest in scaling was partly driven by England's current system of public health commissioning which encourages local policy makers to collaborate with NGOs and work in partnership with programme delivery bodies, increasing opportunities for non-governmental agencies to provide services [62]. This leads us to address how transfer agents work together.

\subsection{What Roles and Who Fulfils Them?}

Policy transfer analysis has presented transfer agents as sender and recipient passing knowledge or programme between them. The collaborative nature of commissioning disrupts this as state and non-state agents cooperate to design policy and implement solutions, drawing on learning from multiple sources. This is epitomised by FFL's approach to evolving the programme for hospitals and other settings by co-developing with pilot institutions:

Working closely with those settings at a strategic level was to make sure that those frameworks would resonate with their strategic priorities and various drivers acting on them and was in the appropriate language. (FFL manager)

FFL, local government officials and institution representatives shared responsibility for adapting programme design, so there is no clear divide between agents responsible for delivery and policy decisions. This may be a facet of a commissioning model which promotes partnership between state 
and non-state actors, but others suggest transfer relationships are rarely organised around bilateral sender-recipient roles [62].

A more fluid account of transfer actors is required because each takes on various roles across the process. The FFL partnership had several related roles in scaling out, firstly, campaigning on poor food in public settings. Secondly identifying and championing best practice, thirdly engaging key decision makers through national events and establishing networks to share their whole setting approach. The partnership convened networks to promote cross-regional exchange between local government officials, and intra-regional sharing between actors involved in public food. Networks transferred solutions by communicating policy ideas $[8,11,41]$. In this role the partnership facilitated learning about FFL, capitalising on decisions makers' tendency to look to close peers for policies [41,43]. FFL's scaling benefited from 'champions' who promoted the programme; the partnership capitalised on this by creating opportunities for commissioners to network. One commissioner described helping FFL scale by advocating it to peers in other areas, and encouraging colleagues in other policy fields to support it. Actors' roles overlapped and worked synergistically because motives aligned around the will to expand the success of a proven programme.

It should be apparent that multiple actors effected FFL scaling, each fulfilling multiple roles. It is also significant that the FFL partnership remained constant across these transfers. The partnership holds knowledge about how to promote food sustainability in public institutions, has skilled staff experienced in working on these issues, and holds resources such as training packages and communication materials. These remain available as the programme moves locations and sectors, making for efficient lower risk delivery. A vital characteristic of FFL as actor driving scaling is its reputation and track record which give decision makers confidence. The continuity of FFL as actor and their will to pursue scaling is significant to this mode of policy transfer; the partnership's history of successful innovation attracts those able to support delivery in new contexts.

Although a constant presence, the FFL partnership has changed in shape, size and ways of working since the programme was born. This suggests that in addition to considering how policies mutate as they move [63] it is important to consider how actors evolve. The partnership grew in terms of staffing and turnover, and developed new funding models for their work; priorities shifted according to how different sectors responded. It is probable that other actors changed through involvement in scaling. This deserves further attention, perhaps supported by an additional analytic question for policy transfer: how do transfer agents change?

\subsection{What Is the Outcome of Scaling, and What Contributes to Success?}

The final two questions in the framework are closely related, addressing the need to assess the results of transfers, firstly by asking whether scaling was successful. Commissioners all regarded FFL as successful in delivering desired outcomes. Programme evaluation supported this conclusion, finding that FFL has a positive impact on food cultures within and beyond schools [64]. During scaling FFL was found to have made good progress bringing healthy sustainable food to more communities through greater geographic coverage of its school's work, diversifying into new settings, and influencing strategic drivers for public food, especially for schools and hospitals. This presented the prospect that the programme accelerated transitions towards sustainable food systems in the local context.

Three factors contributed to FFL's successful scaling. The first is actors' work to distinguish the programme's invariable and variable aspects, and to identify how to apply the former in new situations [29]. The focus on a holistic setting approach to food remained constant; as one commissioner said "the principles are universal no matter what the setting". The programme could retain its core as it scaled out by focusing on institutions sharing the features of being large procurers of food served as a central part of daily life. As the programme scaled out, adapting variable aspects was imperative because institutional settings vary. For example, FFL prepared guidance on sourcing and menus for each setting to accommodate dietary considerations and catering systems whilst retaining key principles. This demonstrates that actors seeking to scale a programme need skills in identifying its 
variable and invariable elements, to understand why an innovation was successful in its original niche, and how success can be replicated.

A second success factor was the reputation and profile of FFL as a programme and the partnership as delivery agent. Promotion of FFL's success in schools prompted institutions to look to the partnership for assistance. Local government officials were happy to expand support for the programme because "we know they are a very professional organisation who deliver" (public health commissioner). The FFL partnership secured commissions by promoting testimonials from current commissioners and influential advocates. Commissioners said they were influenced by knowledge that counterparts adopted the approach and found it worked. Several actors said the organisation's profile helped attract executives to events which encouraged them to support the programme.

A third and related factor is that the partnership influenced various levels of decision making to shape the context for local implementation. The latest national plan for food in schools champions an approach mirroring FFL which commissioners said increased demand for FFL. The partnership influenced the national policy context to be conducive to scaling through pressing for government action and contributions to relevant policy networks. Westley et al. [32] identify such advocacy as a transition pathway and term it scaling up. They suggest social organisations come to recognise their ability to deliver micro-scale change is limited by macro factors, so shift focus to systemic causes. These authors demonstrate that NGOs act across levels, influencing vertical and horizontal policy transfer. An organisation is influential at macro scale because it has "a platform of experience, in-depth knowledge of the field, and established reputation" [32] (p. 256). The scale and success of FFL's innovation made it nationally influential when campaigning for better hospital food. By acting at macro level FFL levered change in institutions they do not work with directly, but this was founded in activity to change practice in certain hospitals to demonstrate a feasible alternative. The partnership's skill in influencing national policy makers contributed to successful programme scaling, demonstrating the iterative relationship between policy and programme with each influencing the other. In this sense local opportunities for scaling out can be understood as being partly contingent upon national policy processes for scaling up. Conversely national context at the 'regime level' also accounts for the challenges the programme has experienced, with limited high level political support for alternative food systems.

Although FFL's scaling can be judged successful it encountered constraints common to policy transfer. Scaling is dependent on the fiscal space [35], in FFL's case investment from commissioners with finite budgets. But the programme seems to have largely avoided other contributors to transfer failure [17]. We suggest three factors helped FFL avoid inappropriate or incomplete transfer. Firstly, the partnership remained a consistent presence across programme transfer. This reduced the risk of insufficient knowledge or skill hampering implementation in new jurisdictions. It provided on-going access to expertise in the programme's invariable aspects and how to deliver them, so avoiding incomplete transfers. Secondly, by working in collaboration with experts in each setting the partnership accessed expertise required to shape variable aspects to suit new contexts, reducing the risk of inappropriate transfers. Finally, the reasons actors involved wanted the programme to scale altered the likelihood of success, hence the significance of analysing motivations.

What motivates policy transfers requires greater attention because it is associated with the likelihood of successful transfer outcomes. The FFL partnership wanted to scale the programme and its achievements, a motive which led them to invest in a strategy for scaling, acquiring funding and expertise to support it. Some spread was achieved through opportunistic diffusion, but widespread replication requires a deliberate strategy and well-resourced, skilled team [31,39]. The desire to scale led the partnership to prioritise this, allowing them to overcome constraints others encounter. But the goal was not policy transfer for its own sake, their ultimate motive was 'good food for all'. Where this seemed unlikely transfers did not proceed, minimising inappropriate transfer.

FFL's ambition to bring good food to all motivated their scaling strategies, in the belief that many people and institutions could benefit from healthy, sustainable food. But not all organisations have 
scaling as a goal and not all innovators look to move beyond niche [65]. Whether scaling is appropriate depends on the purpose of an innovation, and whether it can be met through scaling up and out. For FFL it has been possible to contribute to a more sustainable agri-food system by scaling across space, time, and domains, with commissioners satisfied that the programme has met their objectives. For other innovations, moving up scale may preclude success or have perverse consequences [7], suggesting scaling is not always appropriate transition pathway. The question 'what motivates transfer' seems crucial to assessing the desirability of scaling up and out as the answer is closely linked to factors in successful outcomes.

\section{Conclusions}

This paper has examined how niche innovations influence transitions of the kind sought by proponents of a more sustainable agri-food system, improving understanding of processes involved. The case of Food for Life suggests how scaling up and out an innovative programme can achieve change which might represent a transition pathway. We have characterised this as a specific mode of policy transfer, and demonstrated that its defining features increase the likelihood of successful outcomes, namely the continued involvement of a delivery agent across contexts transferred into. This suggestion deserves further investigation through comparative research into the relative success of different modes of policy transfer and their role in accelerating sustainability transitions [66]. The analytic questions proposed here can help evaluate the relative merits of different modes of transfer, and the likelihood of successful outcomes. In addition to Food for Life, they might also be applied to other types of food sustainability initiatives such as those led by government, private sector and civil society actors.

Our focus on scaling challenges how policy transfer has typically been analysed, in particular revisiting the question 'why transfer?'. Placing policy transfers on a continuum between voluntary and coercive over-simplifies possible drivers, and neglects what motivates agents to attempt a transfer. Closer attention to motivations for transferring policy addresses a gap in understanding why decision makers favour the process. More importantly it supports analysis of the likelihood of success, providing parameters to assess the outcomes. Our framework for policy transfer supports analysis focused on evaluating success and understanding how it is achieved. It allows for complex overlapping roles of actors involved in policy transfer, and their evolution. The case study suggests that future research may pursue the question 'how are actors changed by the process?'.

Analysing how Food for Life achieved positive transfers demonstrates that motivations for transfer affect whether it is successful; had the motive been scaling per se the partnership may have attempted inappropriate transfers. This is an important lesson for scholars of food system transitions who have been guilty of calls for scaling without explaining why this is desirable, or precisely what should be scaled: actors, programmes, practice or outcomes? This risks the aspiration to scale an innovation becoming a goal, driving transfers irrespective of the likelihood of beneficial outcomes. The goal of achieving transition towards sustainability should not be confused with scaling as a potential strategy; making food systems more sustainable requires replication of outcomes conducive to sustainability which might be achieved through scaling, but this is only one potential pathway, and not necessarily the appropriate route.

Acknowledgments: Our thanks to Alan Greer and Amanda Donnelly for comments on versions of this article. This study draws upon research funded by the BIG Lottery Fund and commissioned by the Soil Association.

Author Contributions: Hannah Pitt (H.P.) and Mat Jones (M.J.) jointly conceived, designed and undertook the empirical research that underpins the article; H.P. led the conception, design and literature review for the article; H.P. produced the first full draft of the article; M.J. revised the first draft; H.P. and M.J. collaborated to revise and produce the final draft.

Conflicts of Interest: The authors declare no conflict of interest. The founding sponsors had no role in the design of the study; in the collection, analyses, or interpretation of data; in the writing of the manuscript, and in the decision to publish the results. 


\section{References}

1. Hinrichs, C. Transitions to sustainability: A change in thinking about food systems change? Agric. Hum. Values 2014, 31, 143-155. [CrossRef]

2. Goodman, D.; DuPuis, M.; Goodman, M. Alternative Food Networks. Knowledge, Practice and Politics; Routledge: London, UK, 2012.

3. Marsden, T.; Morley, A. Current food questions and their scholarly challenges: Creating and framing a sustainable food paradigm. In Sustainable Food Systems; Marsden, T., Morley, A., Eds.; Earthscan: London, UK, 2014; pp. 1-29.

4. Marsden, T.; Sonnino, R. Human health and wellbeing and the sustainability of urban-regional food systems. Curr. Opin. Environ. Sustain. 2012, 4, 427-430. [CrossRef]

5. Morgan, K.; Sonnino, R. The School Food Revolution: Public Food and the Challenge of Sustainable Development; Earthscan: London, UK, 2008.

6. Sonnino, R.; Spayde, J. The 'new frontier?' Urban strategies for food security and sustainability. In Sustainable Food Systems; Marsden, T., Morley, A., Eds.; Earthscan: London, UK, 2014; pp. 186-205.

7. Mount, P. Growing local food: Scale and local food systems governance. Agric. Hum. Values 2012, 29, 107-121. [CrossRef]

8. Friedmann, H. Scaling up: Bringing public institutions and food service corporations into the project for a local, sustainable food system in Ontario. Agric. Hum. Values 2007, 24, 389-398. [CrossRef]

9. Morrissey, J.; Mirosa, M.; Abbott, M. Identifying Transition Capacity for Agri-food Regimes: Application of the Multi-level Perspective for Strategic Mapping. J. Environ. Policy Plan. 2014, 16, 281-301. [CrossRef]

10. Smith, A. Green niches in sustainable development: The case of organic food in the United Kingdom. Environ. Plan. C Gov. Policy 2006, 24, 439-458. [CrossRef]

11. Evans, M.; Davies, J. Understanding policy transfer: A multi-level, multi-disciplinary perspective. Public Admin. 1999, 77, 361-385. [CrossRef]

12. Geels, F.; Schot, J. Typology of sociotechnical transition pathways. Res. Policy 2007, 36, 399-417. [CrossRef]

13. Seyfang, G.; Haxeltine, A. Growing grassroots innovations: Exploring the role of community-based initiatives in governing sustainable energy transitions. Environ. Plan. C Gov. Policy 2012, 30, 381-400. [CrossRef]

14. Seyfang, G.; Longhurst, N. Growing green money? Mapping community currencies for sustainable development. Ecol. Econ. 2013, 86, 65-77. [CrossRef]

15. Born, B.; Purcell, M. Avoiding the Local Trap Scale and Food Systems in Planning Research. J. Plan. Educ. Res. 2006, 26, 195-207. [CrossRef]

16. Johnson, R.; Fraser, E.D.; Hawkins, R. Overcoming Barriers to Scaling Up Sustainable Alternative Food Systems: A Comparative Case Study of Two Ontario-Based Wholesale Produce Auctions. Sustainability 2016, 8, 328. [CrossRef]

17. Dolowitz, D.; Marsh, D. Learning from Abroad: The Role of Policy Transfer in Contemporary Policy-Making. Governance 2000, 13, 5-23. [CrossRef]

18. Allen, P.; Guthman, J. From "old school" to "farm-to-school": Neoliberalisation from the ground up. Agric. Hum. Values 2006, 23, 401-415. [CrossRef]

19. Sage, C. Environment and Food; Routledge: London, UK, 2012.

20. Marsden, T.K. From post-productionism to reflexive governance: Contested transitions in securing more sustainable food futures. Int. J. Rural Stud. 2013, 29, 123-134. [CrossRef]

21. Morgan, K. Greening the Realm: Sustainable food chains and the public plate. Reg. Stud. 2008, 42, 1237-1250. [CrossRef]

22. Fairchild, R.; Collins, A.J. Serving up healthy and sustainable school meals? An analysis of school meal provision in Cardiff (UK). J. Environ. Policy Plan. 2011, 13, 209-229. [CrossRef]

23. Markard, J.; Raven, R.; Truffer, B. Sustainability transitions: An emerging field of research and its prospects. Res. Policy 2012, 41, 955-967. [CrossRef]

24. Geels, F. Technological transitions as evolutionary reconfiguration processes: A multi-level perspective and a case-study. Res. Policy 2002, 31, 1257-1274. [CrossRef]

25. Lutz, J.; Schachinger, J. Do local food networks foster socio-ecological transitions towards food sovereignty? Learning from real place experiences. Sustainability 2013, 5, 4778-4796. [CrossRef] 
26. Kirwan, J.; Ilbery, B.; Maye, D.; Carey, J. Grassroots social innovations and food localisation: An investigation of the Local Food programme in England. Glob. Environ. Chang. 2013, 23, 830-837. [CrossRef]

27. Lockie, S.; Halpin, D. The 'conventionalisation' thesis reconsidered: Structural and ideological transformation of Australian organic agriculture. Sociol. Rural. 2005, 45, 284-307. [CrossRef]

28. Darnhofer, I.; Lindenthal, T.; Bartel-Kratochvil, R.; Zollitsch, W. Conventionalisation of organic farming practices: From structural criteria towards an assessment based on organic principles. A review. Agron. Sustain. Dev. 2010, 30, 67-81. [CrossRef]

29. Jowett, A.; Dyer, C. Scaling-up successfully: Pathways to replication for educational NGOs. Int. J. Educ. Dev. 2012, 32, 733-742. [CrossRef]

30. McDonald, S.; Keesler, V.; Kauffman, N.; Scheider, B. Scaling up exemplary interventions. Educ. Res. 2006, 35, 15-24. [CrossRef]

31. Millar, J.; Connell, J. Strategies for scaling out impacts from agricultural systems change: The case of forages and livestock production in Laos. Agric. Hum. Values 2010, 27, 213-225. [CrossRef]

32. Westley, F.; Antadze, N.; Riddell, D.; Robinson, K.; Geobey, S. Five Configurations for Scaling Up Social Innovation: Case Examples of Nonprofit Organizations From Canada. J. Appl. Behav. Sci. 2014, 50, $234-260$. [CrossRef]

33. Westley, F.; Antadze, N. Strategies for Scaling Social Innovation for Greater Impact. Innov. J. Public Sect. Innov. J. 2010, 15, 2-18.

34. Linn, J. (Ed.) Scaling up in Agriculture, Rural Development and Nutrition; International Food Policy Research Institute Washington: Washington, DC, USA, 2012.

35. Hartmann, A.; Linn, J. Scaling up: A Path to Effective Development 2020 Focus Brief; International Food Policy Research Institute Washington: Washington, DC, USA, 2007.

36. World Health Organisation (WHO). Nine Steps for Developing a Scaling-up Strategy; WHO: Geneva, Switzerland, 2010.

37. International Fund for Agricultural Development. Scaling up Toolkit. 2015. Available online: http://www. ifad.org/knotes/scaling_up/index.htm (accessed on 29 July 2016).

38. Snapp, S.; Heong, K. Scaling up and out. In Managing Natural Resources for Sustainable Livelihoods: Uniting Science and Participation; Pound, B., Snapp, S., McDougall, C., Braun, A., Eds.; Earthscan: London, UK, 2013; pp. 67-87.

39. Simmons, R.; Fajans, P.; Ghiron, L. (Eds.) Scaling up Health Service Delivery: From Pilot Innovations to Policies and Programs; WHO: Geneva, Switzerland, 2007.

40. Dolowitz, D. Introduction. Governance 2000, 13, 1-4. [CrossRef]

41. Wolman, H.; Page, E. Policy Transfer among Local Governments: An Information-Theory Approach. Gov. Intl. J. Policy Admin. Inst. 2002, 15, 477-501. [CrossRef]

42. Rose, R. What is Lesson-Drawing? J. Public Policy 1991, 11, 3-30. [CrossRef]

43. Bulkeley, H. Urban sustainability: Learning from best practice? Environ. Plan. A 2006, 38, 1029-1044. [CrossRef]

44. Dolowitz, D. A Policy-maker's Guide to Policy Transfer. Political Quart. 2003, 74, 101-108. [CrossRef]

45. Marsh, D.; Sharman, J. Policy diffusion and policy transfer. Policy Stud. 2009, 30, 269-288. [CrossRef]

46. Lodge, M.; James, O. The limitations of 'policy transfer' and 'lesson drawing' for public policy research. Political Stud. Rev. 2003, 1, 179-193.

47. Benson, D.; Jordan, A. What Have We Learned from Policy Transfer Research? Dolowitz and Marsh Revisited. Political Stud. Rev. 2011, 9, 366-378. [CrossRef]

48. Dwyer, P.; Ellison, N. "We nicked stuff from all over the place": Policy transfer or muddling through? Policy Politics 2009, 37, 389-407. [CrossRef]

49. Stone, D. Transfer and translation of policy. Policy Stud. 2012, 33, 483-499. [CrossRef]

50. Tenemos, C.; McCann, E. Geographies of policy mobilities. Geogr. Compass 2013, 7, 344-357. [CrossRef]

51. Stone, D. Transfer agents and global networks in the 'transnationalization' of policy. J. Eur. Public Policy 2004, 11, 545-566. [CrossRef]

52. Duncan, S. Policy transfer: Theory, rhetoric and reality. Policy Politics 2009, 37, 453-458. [CrossRef]

53. Soil Association. Who We Are. 2016. Available online: http://www.soilassociation.org/aboutus/whoweare (accessed on 29 July 2016).

54. Food for Life. 2016. Available online: http:/ /www.foodforlife.org.uk/about-us (accessed on 29 July 2016). 
55. Soil Association. FAQs about the Hospital Food. Available online: http:/ /www.sacert.org/LinkClick.aspx? fileticket=4Ah2je8pGN8\%3d\&tabid=1613 (accessed on 16 February 2016).

56. Kersley, H.; Knuutila, A. The Benefits of Procuring School Meals through the Food for Life: An Economic Analysis; New Economics Foundation: London, UK, 2011.

57. Jones, M.; Dailami, N.; Weitkamp, E.; Kimberlee, R.; Salmon, D.; Orme, J. Food sustainability education as a route to healthier eating: Evaluation of a multi-component school programme in English primary schools. Health Educ. Res. 2012, 27, 448-458. [CrossRef] [PubMed]

58. Salmon, D.; Jones, M.; Weitkamp, E.; Kimberlee, R.; Orme, J. Take home messages on sustainable food: surveying parent perceptions of the effects of a primary school programme. Br. J. Educ. Soc. Behav. Sci. 2013, 3, 490-503. [CrossRef]

59. Pawson, R.; Tilley, N. Realistic Evaluation; Sage: London, UK, 1997.

60. Connell, J.P.; Kubisch, A.C. Applying a theory of change approach to the evaluation of comprehensive community initiatives: Progress, prospects, and problems. New Approaches Eval. Community Initiat. 1998, 2 , $15-44$.

61. Department of Health. Public Health Outcomes Framework 2013 to 2016; Department of Health: London, UK, 2013.

62. Royal Society for Public Health (RSPH). The RSPH Guide to Commissioning for Health Improvement; RSPH: London, UK, 2014.

63. Peck, J. Geographies of policy: From transfer-diffusion to mobility-mutation. Prog. Hum. Geog. 2011, 35, 773-797. [CrossRef]

64. Jones, M.; Pitt, H.; Orme, J.; Bray, I.; Gary, S.; Kimberlee, R.; Means, R.; Oxford, L.; Powell, J.; Salmon, D.; et al. Evaluation of Food for Life 2013-15. Summary and Synthesis Report; UWE: Bristol, UK, 2016.

65. Hargreaves, T.; Hielscher, S.; Seyfang, G.; Smith, A. Grassroots innovations in community energy: The role of intermediaries in niche development. Glob. Environ. Chang. 2013, 23, 868-880. [CrossRef]

66. Meadowcroft, J. Engaging with the politics of sustainability transitions. Environ. Innov. Soc. Trans. 2011, 1, 70-75. [CrossRef]

(C) 2016 by the authors; licensee MDPI, Basel, Switzerland. This article is an open access article distributed under the terms and conditions of the Creative Commons Attribution (CC-BY) license (http://creativecommons.org/licenses/by/4.0/). 